\title{
Peculiarities of chemical properties of imidazole-derived and other types of cyclic nitrones and their use in Organic Synthesis
}

\author{
Igor A. Grigor'ev \\ N.N.Vorozhtsov Institute of Organic Chemistry Siberian Branch of the Russian Academy of \\ Sciences, 630090, Novosibirsk, Russia \\ E-mail:grig@nioch.nsc.ru
}

Dedicated to Prof. Alexander F. Pozharskii on the occasion of his $70^{\text {th }}$ birthday

\begin{abstract}
Nitrones are still of special interest for researchers both due to a broad spectrum of their application in various spheres of knowledge and their successful use as building blocks in different synthetic strategies. In this connection, the width of their application range makes the search for novel synthetic approaches to nitrones and their chemical transformation an urgent task. Reactivity of nitrones largely depends on their configuration and cyclic nitrones with $E$ configuration are more likely to be chemically modified rather than their acyclic analogues, which allows us to apply new approaches to functional heterocyclic compounds due to the reaction capacity of the nitrone group included into their structure. First of all it concerns the reactions with electrophilic and nucleophilic reagents. Besides, there have been found new methods of nitrone group activation both with nucleophilic reagents by radical cation formation and with electrophilic reagents by generating dipolar-stabilized anions. Electronic structure of active intermediate particles has been studied and a possible explanation for the differences in reactivity of cyclic and acyclic nitrones has been given.
\end{abstract}

Keywords: Complex induced proximity effect, cyclic voltammogram, dipolar-stabilized anion, electrochemical oxidation, metalation, NMR spectra, nitrone, radical cation

\section{Table of Contents}

1. Electrophilic Reactions of Cyclic Nitrones

1.1. Reactions of electrophilic substitution of $\alpha$-alkyl nitrones

1.2. Nitration of $\alpha$-aryl nitrones

1.3. Electrophilic substitution at $\alpha$-carbon atom

1.3.1. Metalation of nitrones 
1.3.2. The effect of nitrone group configuration on H-D- exchange of methyne hydrogen and nitrone metalation.

1.3.3. ${ }^{13} \mathrm{C},{ }^{14} \mathrm{~N}$ and ${ }^{7} \mathrm{Li}$ NMR spectra of dipole-stabilized organolithium derivatives of cyclic nitrones

2. Nucleophilic Reactions of Cyclic Nitrones

2.1. Oxidative alkoxylation of nitrones to $\alpha$-alkoxy nitrones and $\alpha$-alkoxy substituted nitroxyl radicals.

2.2. Oxidative amination of nitrones to $\alpha$-amino-substituted nitroxyl radicals

2.3. Oxidative fluorination of nitrones to $\alpha$-fluorosubstituted nitroxyl radicals

3. Conclusions

\section{Introduction}

In the chemistry of heterocyclic compounds there is a well-known $N$-oxide group effect which leads to a substantial change in reactivity of heteroaromatic $N$-oxides, as compared to their unoxidized analogues, activating them to electrophilic, nucleophilic and radical agents. ${ }^{1}$

For the last 50 years many scientists have drawn special attention to nitrones due to their successful application as building blocks in the synthesis of various natural and biologically active compounds, of stable nitroxyl radicals and of other important products for special purposes $^{2}$ as well as spin traps for the study of radical processes including those which take place in biological systems, ${ }^{3}$ and they also found use as both, modifiers and regulators of molecular weight in radical polymerization. ${ }^{4}$

The recent monograph ${ }^{2}$ gives the contemporary analysis of nitrone chemistry. According to the literature, nitrone reactivity and, as a consequence, the possibility of their chemical modification largely depends on the configuration of nitrone grouping $-E$ or $Z$.

To illustrate, cyclic aldonitrones (the nitrones with a proton at $\alpha$-carbon atom) (I) always have fixed E-configuration, whereas it is typical of acyclic aldonitrones (II) to have $Z$ configuration of the nitrone group (Scheme 1). Besides, cyclic nitrones are of significantly higher stability to both acids and bases, which allows us to use rigit reaction conditions for their chemical transformations, which in case of acyclic nitrones could cause their destruction. Due to such structural distinctions, cyclic nitrones with almost all possible chemical modifications typical of acyclic nitrones have a whole range of specific chemical properties which seem to increase the possibilities for their chemical modification in comparison with their acyclic analogues. 
<smiles>[O-][N+]1=CCCCC1</smiles>

I<smiles>[R]C=[N+]([R])[O-]</smiles>

II

E - configuration

Z- configuration<smiles>C#CC1=[N+]([O-])CCCC1</smiles><smiles>CC1(C)C=[N+]([O-])C(C)(C)C1</smiles><smiles>[R]N1C(C)(C)C([2H])=[N+]([O-])C1(C)C</smiles><smiles>[R]C1=NC(C)(C)[N+]([O-])=C1</smiles><smiles>[R]C1=[N+]([O-])C(C)(C)[N+]([O-])=C1</smiles><smiles>[R]C1=NC=[N+]([O-])C1(C)C</smiles><smiles>[R]C1=[N+]([O-])C=[N+]([O-])C1(C)C</smiles><smiles>CC1(C)Cc2ccccc2C=[N+]1[O-]</smiles>

\section{Scheme 1}

The given review is aimed at making a comparative analysis of chemical transformations typical of cyclic nitrones (I) and unknown for acyclic nitrones (II). Scheme 2 (reactions 5-10) shows transformations specific for cyclic nitrones. We made an attempt to interpret the differences in reaction capacity of both cyclic and acyclic nitrones connected with the structure of their nitrone groupings. Most of the results have been obtained in the Novosibirsk Institute of Organic Chemistry, Siberian Branch of the Russian Academy of Sciences.

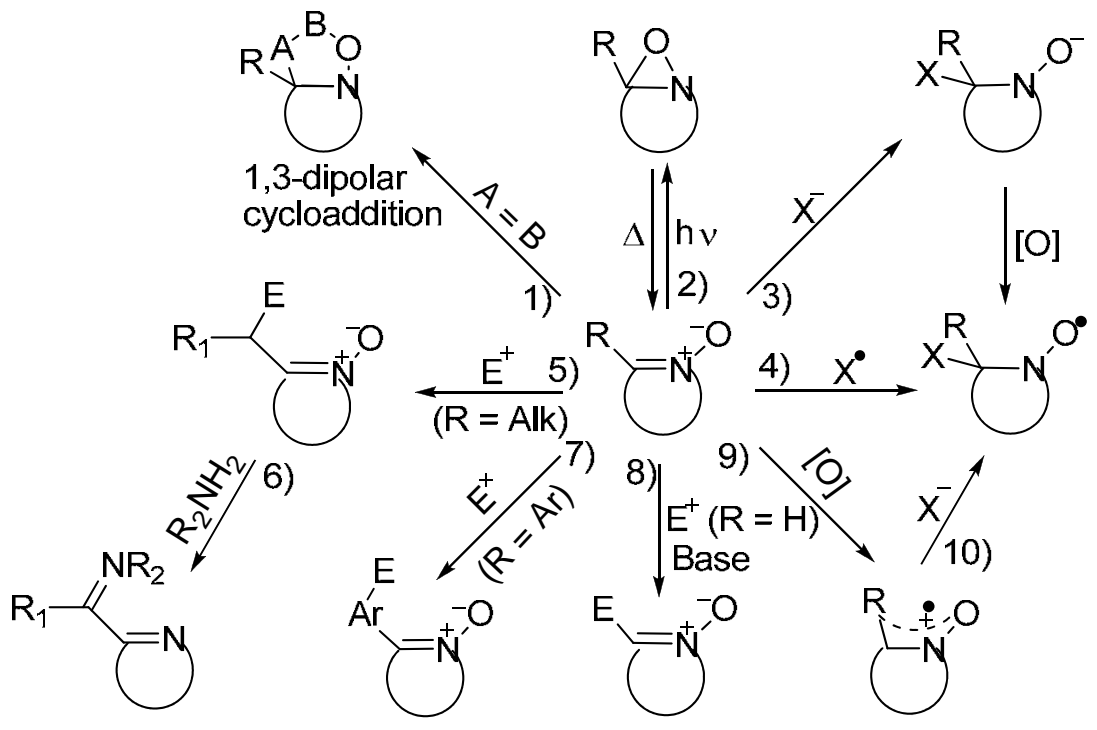

\section{Scheme 2}




\section{Electrophilic Reactions of Cyclic Nitrones}

\subsection{Reactions of electrophilic substitution of $\alpha$-alkyl nitrones}

Nitrones with protons in the $\alpha$-alkyl group can occur in tautomeric nitrone-hydroxylamine equilibrium (Scheme 3) similar to keto-enol and imine-enamine tautomerisms. ${ }^{2}$

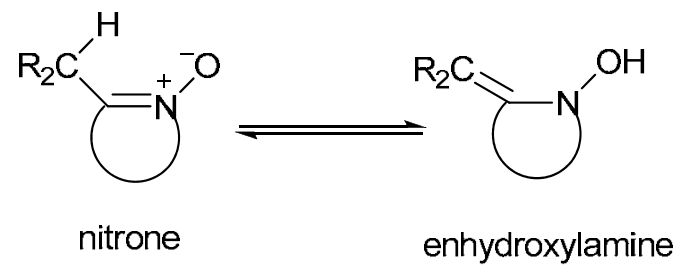

\section{Scheme 3}

Generation of the enhydroxyamine as well as enol forms takes place upon treatment with both bases and acids; the reaction with $\alpha$-alkyl nitrones in $\mathrm{D}_{2} \mathrm{O}$ shows a quick deutero exchange. ${ }^{5}$

The reaction of nitrones of the 3-imidazoline series 1 with bromine and amyl nitrite, in the presence of bases, gives $\alpha$-tribromomethyl- $\mathbf{2}$ and $\alpha$-hydroxyliminomethyl- $\mathbf{3}$ derivatives (Scheme 4). ${ }^{6}$ Bromination of nitrones 1 with $N$-bromosuccinimide in $\mathrm{CCl}_{4}$ or bromine in methanol leads to the formation of $\alpha$-bromoalkyl- $\mathbf{4 a , b}$ and $\alpha$-dibromomethyl- $\mathbf{5}$ nitrones. ${ }^{7-9}$ The reaction with iodine in methanol gives the iodo derivative $6,{ }^{9}$ whereas the reaction with $N$ chlorosuccinimide in $\mathrm{CCl}_{4}$ leads to $\alpha$-chloroethyl nitrones $7 .{ }^{10}$ Nitrosation in acid medium of $\alpha$ bromomethyl nitrone $\mathbf{4 a}\left(\mathrm{R}^{2}=\mathrm{CH}_{3}\right)$ affords the chloro anhydride of hydroxymic acid $\mathbf{8}$, which is a precursor of nitrile $N$-oxide. ${ }^{9}$

Crotone-type products 9 have been obtained in reactions of 4-methyl-3-imidazoline-3-oxide (1a) $\left(\mathrm{R}^{2}=\mathrm{OH}\right)$ with benzaldehyde and its derivatives ArCHO, where $\mathrm{Ar}=p$-ethynyl -, $p$-bromo and $p$-iodo- phenyl groups ( Scheme 4). ${ }^{6,11,12}$

Alkyl nitrones 1 can be metallized upon treatment with phenyl lithium in ether solution, producing Li-derivatives which react with carboxylic acid esters to give $\beta$-oxo nitrones $\mathbf{1 0}$ - the analogues of $\beta$-diketones. ${ }^{13}$ With the help of the ${ }^{13} \mathrm{C}$ NMR method it has been found that $\beta$-oxo nitrones $\mathbf{1 0}$ exist as an equilibrium mixture of three tautomeric forms with the prevalence of enol nitrone $\mathbf{C}$ and enhydroxyamino nitrone $\mathbf{B}$ forms. The sulfur-containing analog $\mathbf{1 1}$ in $\mathrm{CDCl}_{3}$ and DMSO solutions exists only in the enhydroxy-aminothioxo structure (Scheme 4). ${ }^{14,15}$ 

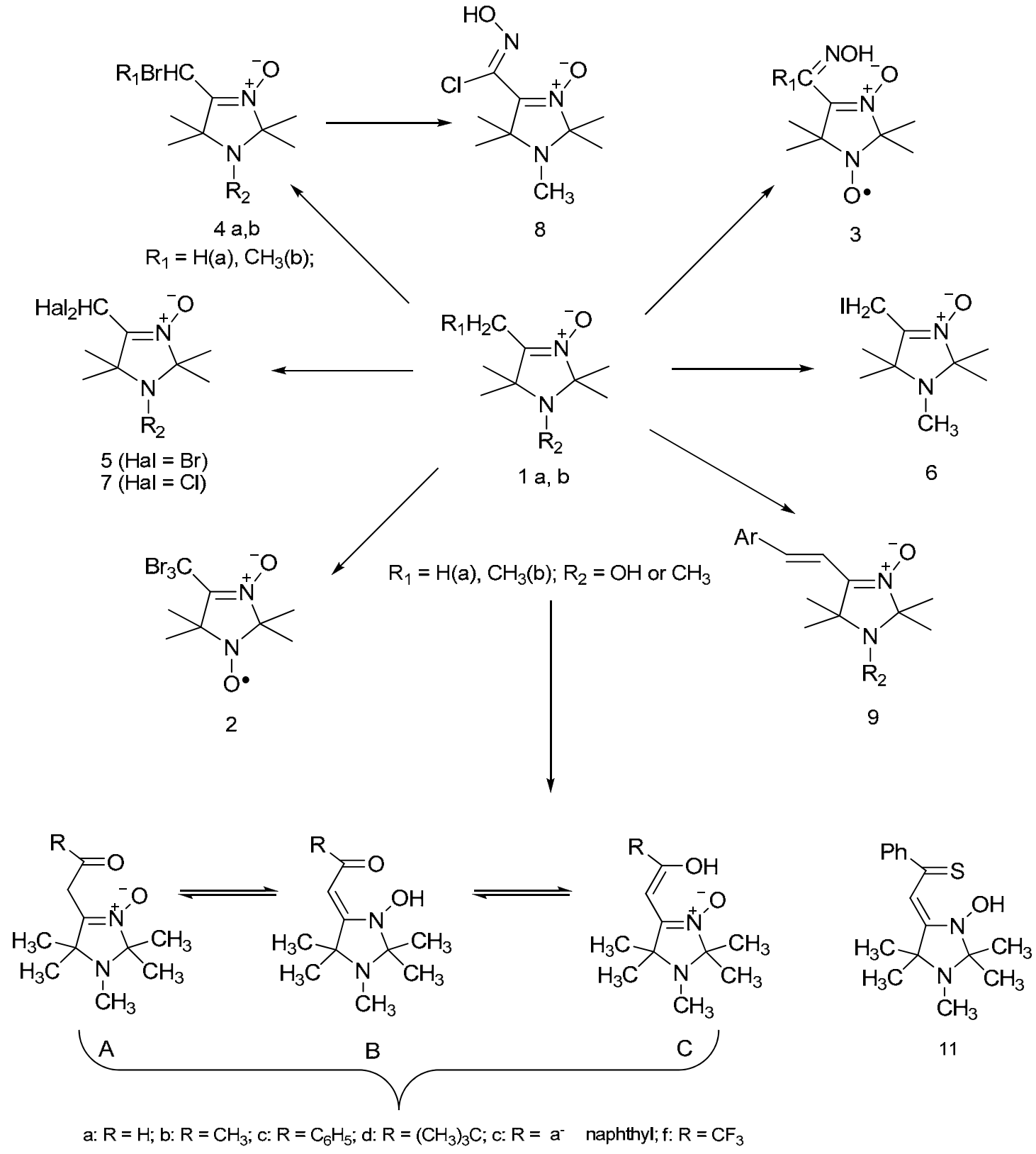

10

\section{Scheme 4}

\subsection{Nitration of $\alpha$-aryl nitrones}

Another example of peculiar properties of cyclic nitrones specified by their greater stability towards rigid reaction conditions in comparison to acyclic nitrones is nitration of $\alpha$-aryl nitrones 12a-c (Scheme 5). 

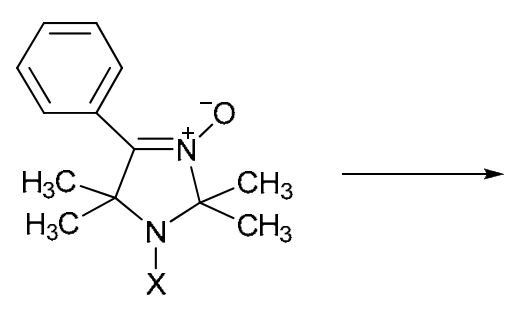

12 a

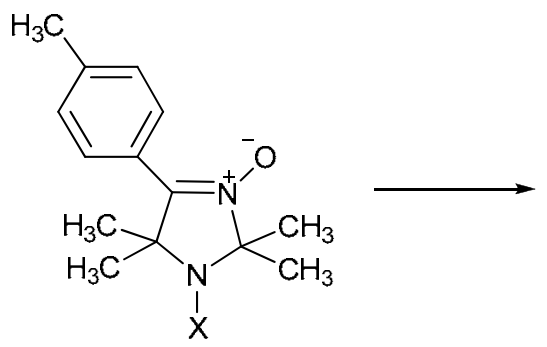

$12 \mathrm{~b}$

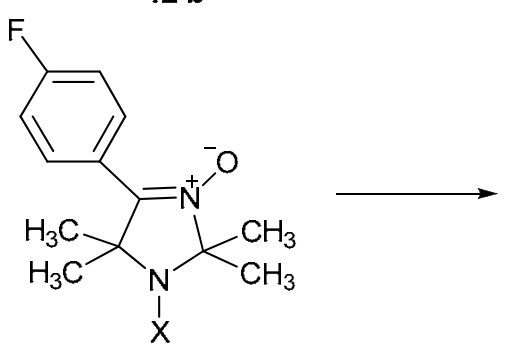

$12 \mathrm{c}$

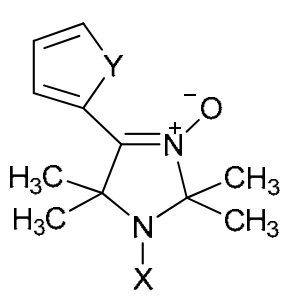

$14 a, b$

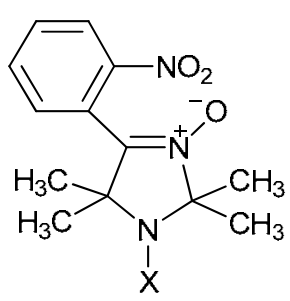

$13 \mathrm{a}$, ortho<smiles>[X]N1C(C)(C)C(c2ccc(C)c([N+](=O)[O-])c2)=[N+]([O-])C1(C)C</smiles>

$13 \mathrm{~b}$<smiles>[X]N1C(C)(C)C(c2ccc(F)cc2[N+](=O)[O-])=[N+]([O-])C1(C)C</smiles>

$13 \mathrm{c}$

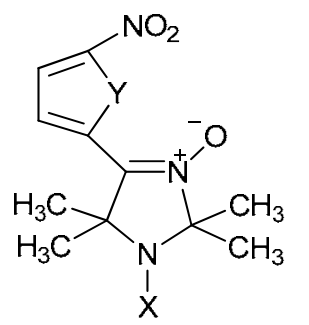

$15 \mathrm{a}, \mathrm{b}$
$2: 1$

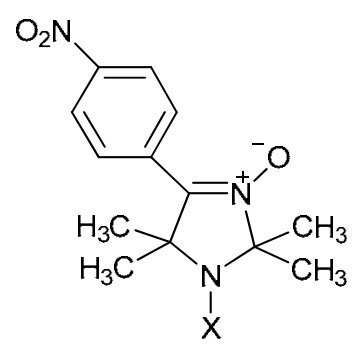

13 a, para

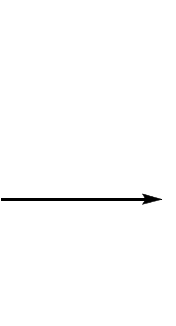

$\mathrm{X}=\mathrm{O}^{\bullet}, \mathrm{OH}, \mathrm{NO}_{2}, \quad \mathrm{Y}=\mathrm{O}(\mathrm{a}), \mathrm{S}(\mathrm{b})$

\section{Scheme 5}

The reactions of electrophilic substitution in $\alpha$-aryl nitrones haven't been studied in depth yet, and at present, the only reported reaction is the nitration of derivatives of 4-aryl-(12a-c) and 4-(2-hetaryl)-3-imidazoline-3-oxides (14a,b). ${ }^{16,17}$ Nitration takes place in concentrated sulphuric acid upon treatment with $\mathrm{HNO}_{3}$. The nitrone group in 4-phenyl-3-imidazoline-3-oxides (12a) is known to be ortho-para-directing in the phenyl ring. The direction of $\alpha$-aryl- $\mathbf{1 2 b}$,c and $\alpha$ hetaryl- 14a nitrations, in more active aromatic systems than in unsubstituted $\alpha$-phenyl nitrone 
12a, is determined first and foremost by the orientation properties of the aromatic system per se. Thus, the $p$-tolyl group in $\mathbf{1 2 b}$ is nitrated in the $m$-position, while the $p$-fluoroderivative $\mathbf{1 2 c}$ in the $o$-position to the nitrone group. Hetaryl derivatives $14 \mathbf{a}, \mathbf{b}$ are nitrated only in the $\alpha$-position of the hetero atom, giving nitro hetarylderivatives $\mathbf{1 5 a}, \mathbf{b}$ (Scheme 5).

The obtained nitroaryl nitrones $\mathbf{1 3}$ and $\mathbf{1 5}$ were reduced into amino aryl nitrones with hydrazine and $\mathrm{Ni}$ Raney. ${ }^{18}$ It is relevant to notice that in such reduction conditions deoxygeneration of nitrone group does not occur.

\subsection{Electrophilic substitution at $\alpha$-carbon atom}

1.3.1. Metalation of nitrones. Direct introduction of functional group to $\alpha$-carbon atom seems possible by means of successive metalation - electrophilic substitution in the series of aldo nitrones. These reactions produce dipole-stabilized carbanions resulted from metalation of cyclic aldo nitrones witn LDA or BuLi .

Metalation of cyclic aldo nitrones in the absence of an "external" electrophile gives dimeric compounds, the non-metalated aldo nitrone group being the electrophile. At the same time, depending on the structure of the starting aldo nitrone, the reaction can give either dimers with two conjugated nitrone groups (route A), or dimers with coupled nitrone and imine groups (route B). ${ }^{19}$
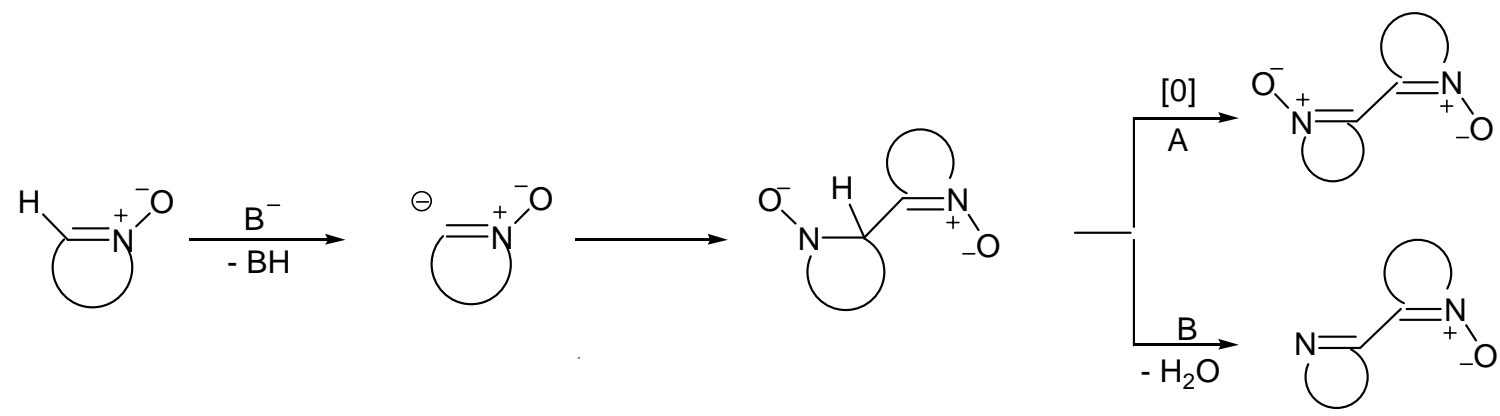

Metalated cyclic aldo-nitrones $\mathbf{1 6}$ and $\mathbf{1 7}$ are characterized by high reactivity towards electrophilic reagents. They react with aldehydes and ketones giving $\alpha$-hydroxymethyl substituted derivatives of nitrones 18 and 19. ${ }^{20}$ The reactions were also carried out with a number of aliphatic, aromatic and hetero-aromatic aldehydes and ketones (Scheme 7). 


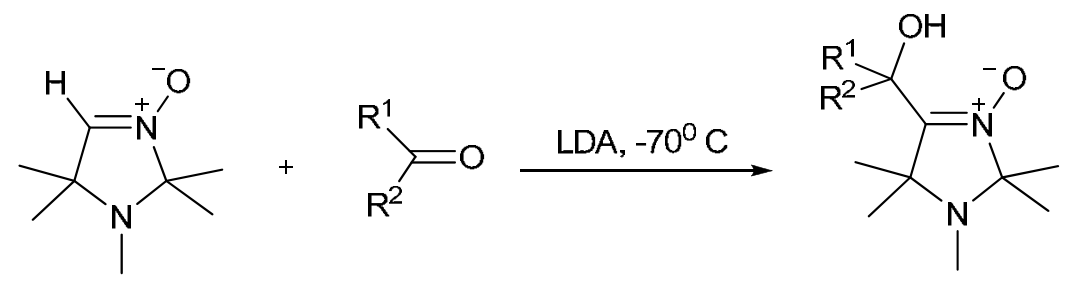

16

18

$\mathrm{R}^{1}=\mathrm{H}, \mathrm{CH}_{3}, \mathrm{Ph}$

$\mathrm{R}^{2}=\mathrm{CH}_{3}, \mathrm{Ph}, \mathrm{CH}_{2}=\mathrm{CH}-, \mathrm{CH}_{2}=\mathrm{CH}-\mathrm{CH}_{2}-\mathrm{CH}_{2^{-}}$,2-Thienyl, 2-Pyridyl, 2-Pyrryl, Ferrocenyl

$\mathrm{R}^{1}+\mathrm{R}^{2}=-\left(\mathrm{CH}_{2}\right)_{5},-\left(\mathrm{CH}_{2}\right)_{4^{-}},-\left(\mathrm{CH}_{2}\right)_{11^{-}},-\mathrm{CH}_{2}-\mathrm{C}\left(\mathrm{CH}_{3}\right)_{2}-\mathrm{N}-\mathrm{C}\left(\mathrm{CH}_{3}\right)_{2}^{-}$<smiles>CC1(C)N=C(c2ccccc2)C=[N+]1[O-]</smiles>

17

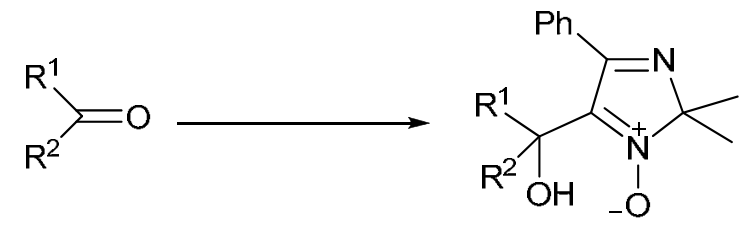

19

$\mathrm{R}^{1}=\mathrm{H}, \mathrm{CH}_{3}$

$\mathrm{R}^{2}=\mathrm{CH}_{3}, \mathrm{Ph},\left(\mathrm{CH}_{3}\right)_{2} \mathrm{C}=\mathrm{CH}-\left(\mathrm{CH}_{2}\right)_{2}, \mathrm{C}\left(\mathrm{CH}_{3}\right)=\mathrm{CH}-, \mathrm{CH}_{2}=\mathrm{CH}-\mathrm{CH}_{2}-\mathrm{CH}_{2^{-}}$

\section{Scheme 7}

With a terminal double bond to the nitrone group in the $\alpha$-hydroxymethyl derivative 20, a typical 1,3-dipolar cycloaddition of nitrones gives compound 21, with the structure being a heterocyclic analog of naturally occurring tricyclic sesquiterpenes (Scheme 8).<smiles>CC1(C)N=C(c2ccccc2)C=C1CCCCCO</smiles>

17

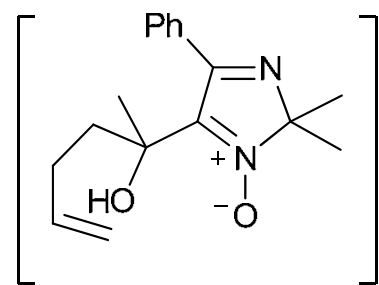

20

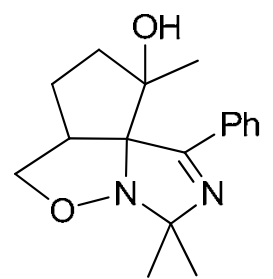

21

\section{Scheme 8}

The reaction of metalated aldo nitrones 16, performed with $\mathrm{Me}_{3} \mathrm{SiCl}, \mathrm{PhSSPh}, \mathrm{PhSeSePh}$, $\mathrm{Ph}_{2} \mathrm{P}(\mathrm{O}) \mathrm{Cl}$ and $\mathrm{Ph}_{2} \mathrm{PCl}$ generates nitrones 22a-e with $\alpha$-carbon-heteroatom bonds. The reaction with $\mathrm{TsCl}$ gives $\alpha$-chloro nitrone $\mathbf{2 2 f}$, and with $\mathrm{TsF}$, the corresponding sulfonyl derivative $\mathbf{2 2 g}$. Using $\mathrm{HgCl}_{2}, \mathrm{Et}_{3} \mathrm{GeCl}, n$ - $\mathrm{Bu}_{3} \mathrm{SnBr}$ as electrophilic reagents, the synthesis of nitrones containing an $\alpha$-carbon-metal bond $\mathbf{2 2} \mathbf{h}$-j and $\mathbf{2 3 \mathbf { k }}$ has been carried out for the first time ${ }^{21,22}$ (Scheme 9). 


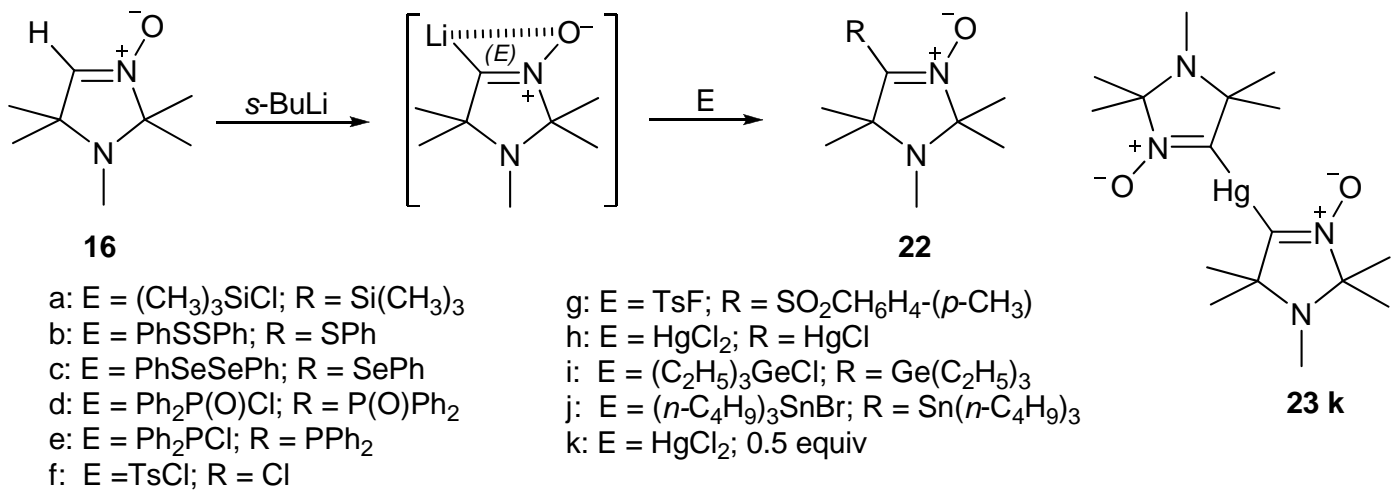

\section{Scheme 9}

Thus, metalation of cyclic nitrones, followed by successive reactions with electrophilic reagents serves as a synthetic method toward $\alpha$-heteroatom substituted nitrones, which are inaccessible by other methods. It is noteworthy that these reactions can take place only with cyclic nitrones with $E$-configuration of the aldo-nitrone group.

\subsubsection{The effect of nitrone group configuration on H-D- exchange of methyne hydrogen} and nitrone metalation. The work ${ }^{23}$ gives experimental data which show that the readiness of aldo nitrones toward metalation and H-D-exchange is determined by the configuration of the nitrone group. This spatial requirement is connected with the fact that deprotonation is carried out in the complex formed by the organolithium compound or alcoholate and the oxygen of the nitrone group at a stage immediately preceding the proton removal. The formation of this complex kinetically facilitates proton removal from the syn-position to the $N$-oxide group. Participation of such a complex in deprotonation proves that metalation of aldo nitrones is a CIPE controlled process (Complex Induced Proximity Effect) ${ }^{24}$ (Scheme 10).
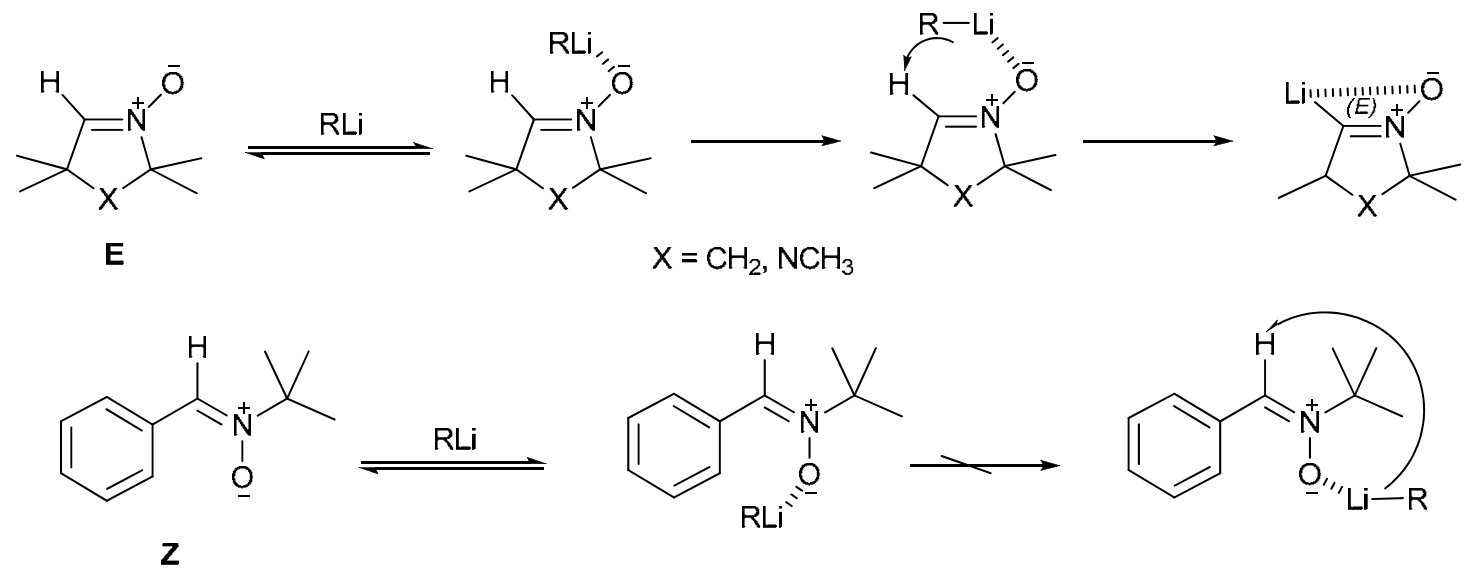

\section{Scheme 10}




\subsection{3. ${ }^{13} \mathrm{C},{ }^{14} \mathrm{~N}$ and ${ }^{7} \mathrm{Li}$ NMR spectra of dipole-stabilized organolithium derivatives of cyclic} nitrones. NMR spectra of the compound resulted from metalation of the cyclic aldonitrone 1,2,2,5,5-pentamethyl-3-imidazoline-3-oxide (16) have been first cited in the work. ${ }^{25}$ The chemical shift of the $\alpha-\mathrm{C}$ atom is located in the region typical of both carbanion and carbenoid carbon atoms (213.14 ppm). The ${ }^{14} \mathrm{~N}$ NMR spectrum of the metalated fragment $\mathbf{2 4 a - c}$ and the calculated charge distribution data in a model compound show a considerable contribution of the carbenoid form $\mathbf{2 4 b}$ ground state structure (Scheme 11).

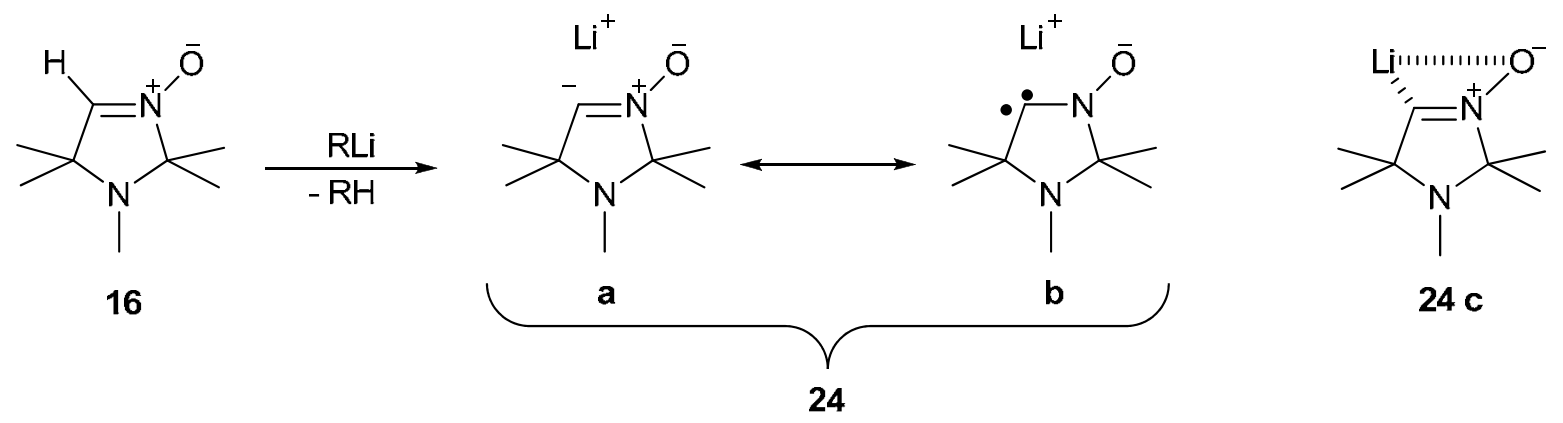

\section{Scheme 11}

\section{Nucleophilic Reactions of Cyclic Nitrones}

\subsection{Oxidative alkoxylation of nitrones to $\alpha$-alkoxy nitrones and $\alpha$-alkoxy substituted nitroxyl radicals}

In the reaction of oxidative methoxylation of heterocyclic nitrones of $4 \mathrm{H}$-imidazole-1,3-dioxide derivatives (24) in methanol with treatment of lead dioxide for the first time there has been obtained direct experimental evidence of the possibility to realize radical cation route of nucleophilic addition to nitrones. ${ }^{26-28}$ As a result of these reactions, high total yields of stable radicals of two types - nitronyl nitroxyl radicals of 2-imidazoline-3-oxide (26) and nitroxyl radicals of 3-imidazoline-3-oxide (27) - has been obtained. Such a reaction route is referred to as "inverted spin trapping"; this route is an alternative to a "conventional spin trapping". 29-33 Realization of either mechanism depends on the reaction conditions, i.e. on the strength of both nucleophile and oxidant. The use of strong oxidants in weak nucleophilic media tends to favour the radical cation mechanism.

Radical cations (RCs) 25 have been registered in electrochemical oxidation of $4 H$-imidazole -1,3-dioxides (24) in dry $\mathrm{CH}_{2} \mathrm{Cl}_{2}$ at $-80^{\circ}--40^{\circ} \mathrm{C}$, with cyclic voltammogram (CVA) corresponding to one-electron reversible oxidation ( $\mathrm{E}_{\mathrm{p}} 0,9-1,3 \mathrm{~V}$ vs.sce) to RCs $\mathbf{2 5}{ }^{34}$

Formation of RC 25 is proved by EPR-spectra registration in the same temperature range in an electrochemical cell placed in the EPR-spectrometer cavity resonator. The HFI of the observed EPR-spectra RCs $\mathbf{2 5}$ are determined by the interaction of unpaired electron with two nuclei ${ }^{14} \mathrm{~N}$ : 25a $-6,76$ and 4,72 G; 25b $-6,97$ and 4,39 G; 25c $-7,74$ and 6,02 G; 25d $-5,33$ and 
5,33 G. The HFI coupling constant was established on the basis of EPR-spectral analysis of RC $(\mathbf{2 5 a})$, labeled by ${ }^{15} \mathrm{~N}$ isotope in position 1 of the heterocycle, and by quantum-chemical calculation. ${ }^{35}$ Direct experimental evidence of radical cation route of the reaction has been obtained on the basis of electrochemical oxidation analysis of $\mathbf{2 4}$ in the presence of nucleophile $\mathrm{MeOH}^{35,36}$ It has been shown that in the electrochemical oxidation of $\mathbf{2 4}$ RC $\mathbf{2 5}$ is initially formed which further reacts with methanol yielding nitronyl nitroxyl derivative 2-imidazoline-3oxide (26a) and nitroxyl radical 3-imidazoline-3-oxide (27a) as a result of the nucleophilic attack at both carbon atoms $\mathrm{C}_{2}$ and $\mathrm{C}_{5}$ of oxidized dinitrone grouping of $\mathrm{RC} \mathbf{2 5}$. The ratio of the reaction products depends on electronic character of the substituents $\mathrm{R}^{1}$ and $\mathrm{R}^{2}$ : the donor nature of $\mathrm{R}^{1}$ and acceptor nature of $\mathrm{R}^{2}$ favors the formation of nitroxyl radicals 27 , whereas the yield of nitronyl nitroxyl radicals 26 increases with the inverse influence of the substituents. It seems important to mention that the yields and the ratio of two products obtained in preparative electrochemical oxidative methoxylation are similar to those observed when $\mathrm{PbO}_{2}$ or $\mathrm{MnO}_{2}$ is used as an oxidant, which is sure to be a direct indication of radical cation route (Scheme 12). ${ }^{35,36}$

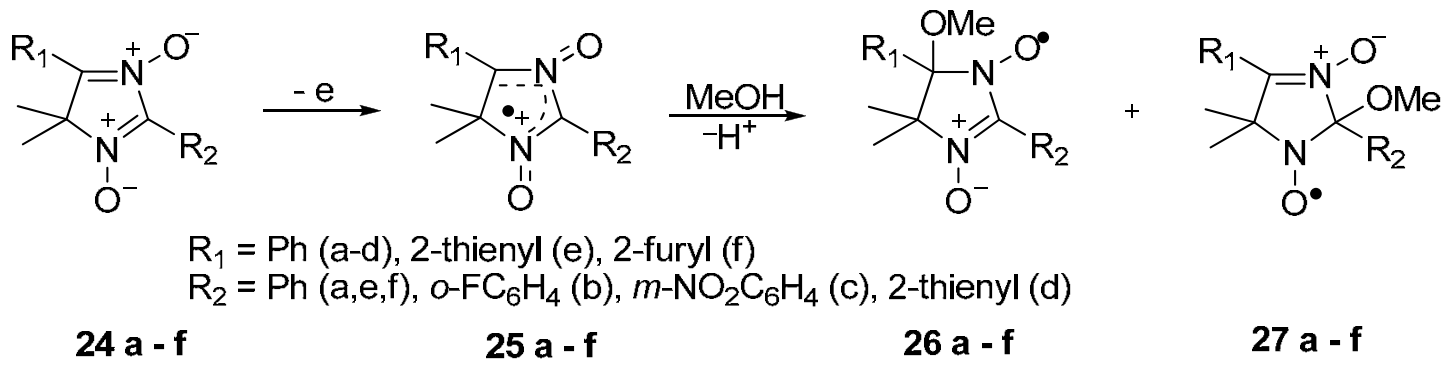

\section{Scheme 12}

In the similar conditions of oxidation of mono- $N$-oxides $4 H$-imidazole (28) and (29) there have been obtained stable nitroxyl radicals $\mathbf{3 0}$ and iminonitroxyl radicals $\mathbf{3 1}$ - $\mathbf{3 3}$ (Scheme 13), ${ }^{28}$ at the same time, oxidation of oxazolidine derivatives $\mathbf{3 4}$ resulted in the synthesis of oxazolidine nitroxyl radicals $\mathbf{3 6} .^{37}$ 
<smiles>[R]C1=NC([R1])(OC)C(C)(C)N1[O]</smiles>

31<smiles>[R]C1=NC([R])=[N+]([O-])C1(C)C</smiles>

28

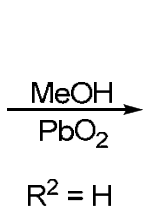

$\mathrm{R}^{2}=\mathrm{H}$<smiles>[R]C1=NC(OC)(OC)N([O])C1(C)C</smiles>

30<smiles>[R]C1(OC)N=C(OC)N([O])C1(C)C</smiles>

32<smiles>[R]C1=NC(C)(C)C([R])=[N+]1[O-]</smiles>

29<smiles>[R]C1=NC(C)(C)C([R1])(OC)N1[O]</smiles>

33

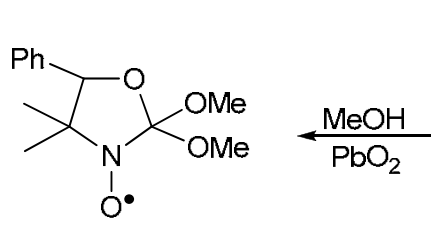

34<smiles>[R]C1OC(c2ccccc2)C(C)(C)N1O</smiles>

35

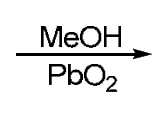

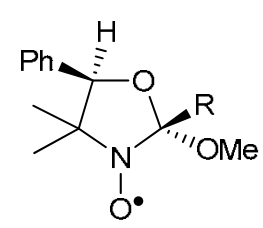

(A)<smiles>[R]C=[N+]([O-])C(C)(C)C(O)c1ccccc1</smiles>

$\mathrm{R}=\mathrm{Ph}(\mathrm{a}), 3-\mathrm{NO}_{2}-\mathrm{C}_{6} \mathrm{H}_{4}(\mathrm{~b}), 2-\mathrm{Py}(\mathrm{c}), \mathrm{H}(\mathrm{d}), \mathrm{CH}_{3}(\mathrm{e}), \mathrm{COOMe}(\mathrm{f})$.

\section{Scheme 13}

In addition to $4 H$-imidazole and oxazolidine derivatives, the reaction of oxidative methoxylation was also used with other cyclic aldo-nitrones: DMPO, derivatives of 3imidazoline-3-oxide (37) and derivatives of $2 \mathrm{H}$-imidazole $(38)^{39}$ and (39). ${ }^{40}$ In these reactions, the formation of stable nitroxyl radicals containing two methoxy groups at the $\alpha$-carbon atom of the nitroxyl group was observed. In some cases, $\alpha$-methoxy nitrone $\mathbf{M N}$ intermediates have also been detected ${ }^{38}$ (Scheme 14). 


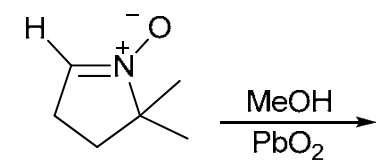

DMPO

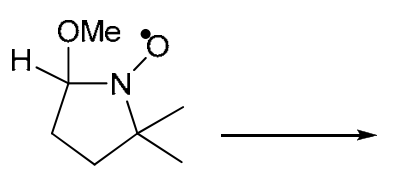

MN

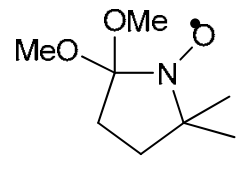

40<smiles>[R]N1C(C)(C)C([2H])=[N+]([O-])C1(C)C</smiles>

$\underset{\mathrm{PbO}_{2}}{\stackrel{\mathrm{MeOH}}{\longrightarrow}}$<smiles>[R]N1C(C)(C)N([O])C([2H])(C)C1(C)C</smiles>

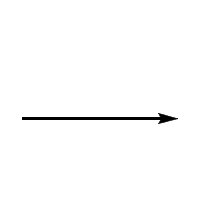<smiles>[R]N1C(C)(C)C(OC)=[N+]([O-])C1(C)C</smiles>

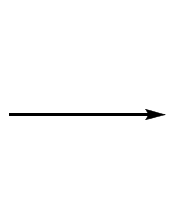

37

$\mathrm{R}=\mathrm{H}, \mathrm{CH}_{3}, \mathrm{OCH}_{3}, \mathrm{NO}, \mathrm{NO}_{2}$<smiles>[R]N1C(C)(C)N([O])C(OC)(OC)C1(C)C</smiles>

41<smiles></smiles><smiles>[R]C1=[N+]([O-])C(C)(C)N([O])C1OC</smiles><smiles>CCCCC</smiles><smiles>[R]C1=[N+]([O-])C(C)(C)[N+]([O-])=C1OC</smiles><smiles>CI</smiles>

38<smiles>[R]C1=NC(C)(C)[N+]([O-])=C1[R]O[Na]</smiles>

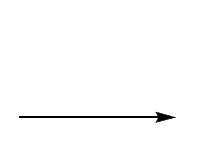<smiles>[R]C1=NC(C)(C)[N+]([O-])=C1OC</smiles>

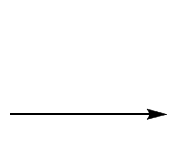

39

\section{Scheme 14}

It seems relevant to note that only cyclic aldo-nitrones tend to react in oxidative alkoxylations to give $\alpha, \alpha$-dialkoxy-substituted nitroxyl radicals. However, the only exception is methylene nitrone 44 which on oxidative methoxylation gives the $\alpha, \alpha, \alpha$-trimethoxy-substituted nitroxyl radical 45 . This is due to the proton in methylene nitrone 44 which, as in case of cyclic nitrones, exists in the cis-position to the $N$-oxide oxygen $^{41}$ (Scheme 15).

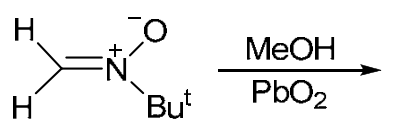

44<smiles>CON(CBr)C(OC)(OC)OC</smiles>

45

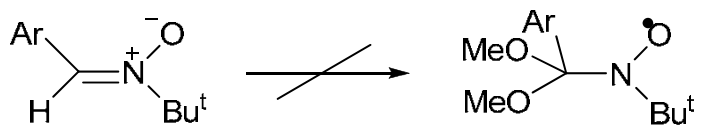

\section{Scheme 15}


Besides, one should mention that in spite of the similar electronic structures, PBN and the isoquinoline nitrone 46 react in a different way. Under no circumstances does PBN give an oxidative methoxylation product, whereas nitrone 46 reacts readily to form $\alpha, \alpha$-dialkoxysubstituted nitroxyl radical $48 .^{41}$ Perhaps this difference might be due to the ability to form a complex with methanol in aldo-nitrones with $E$-configuration and lack of such an ability in PBN with Z-configuration. The complex formation, in turn, seems to favor a fast nucleophilic addition of methanol to the radical cation $\mathbf{4 6}$ formed in the oxidation step. The $\alpha$-methoxy nitrone $\mathbf{4 7}$ obtained in the initial methoxylation has a much lower oxidation potential than the initial aldonitrone. ${ }^{42-44}$ Its oxidation to the radical cation and subsequent reaction with methanol results in the formation of the $\alpha, \alpha$-dimethoxy-substituted nitroxyl radicals (Scheme 16).

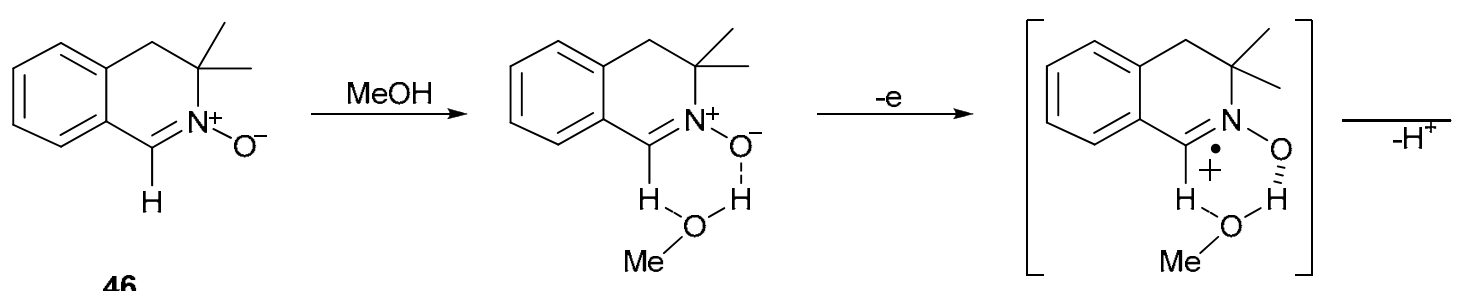

46<smiles>COC1c2ccccc2CC(C)(C)N1O</smiles><smiles>[O-][N+](=Cc1ccccc1)c1ccccc1</smiles><smiles>COC1=[N+]([O-])C(C)(C)Cc2ccccc21</smiles>

47

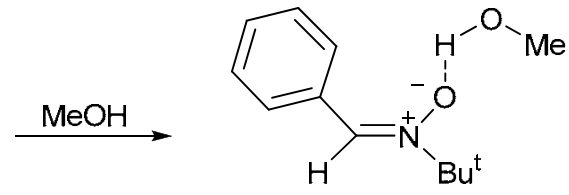

RC

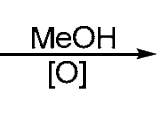

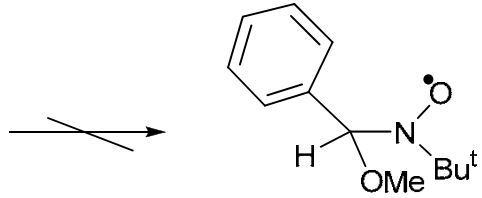<smiles>COC1(OC)c2ccccc2CC(C)(C)N1[O]</smiles>

48

\section{Scheme 16}

In contrast to the reaction conditions of oxidative alkoxylation, the reaction of acid-catalyzed nucleophilic addition of alcohols to derivatives of $4 H$-imidazol- $N, N$-dioxide (24) leads only to nitronyl nitroxyl radicals $26^{45}$

\subsection{Oxidative amination of nitrones to $\alpha$-amino-substituted nitroxyl radicals}

Similar to the oxidative methoxylation reaction, oxidative amination of $4 H$-imidazole $N$-oxides, in amine saturated alcohol solutions, give stable nitroxyl 49, nitronyl nitroxyl 50, imino nitroxyl

51 and 52 radicals with the amino group at the $\alpha$-carbon atom of the nitroxyl group (Scheme 17). ${ }^{46,47}$ The observed influence of substituents on the ratio of amination products at $\mathrm{C}_{2}$ and $\mathrm{C}_{5}$ 
atom is close to the ratio observed in the previously mentioned oxidative methoxylation reaction. In this case it allows us to draw a conclusion about the preference of the radical cation reaction route.

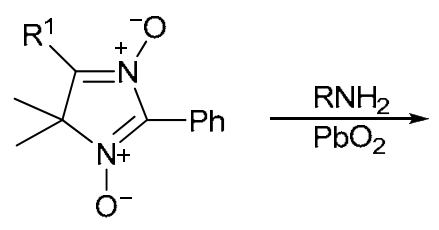

25<smiles>[R]NC1(c2ccccc2)N([O])C(C)(C)C([R])=[N+]1[O-]</smiles>

49<smiles>[R]NC1([R1])N([O-])C(c2ccccc2)=[N+]([O-])C1(C)C</smiles>

50

$\mathrm{R}=\mathrm{H}$ or $\mathrm{CH}_{3} ; \mathrm{R}^{1}=\mathrm{Ph}, 2-\mathrm{Pyridyl}, 2-$ Thienyl, 2-Furyl

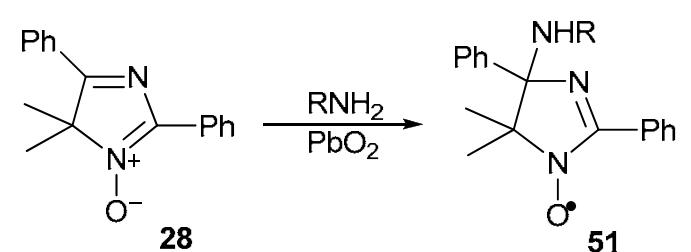

$\mathrm{R}=\mathrm{H}(\mathrm{a}), \mathrm{CH}_{3}(\mathrm{~b})$<smiles>CC1(C)N=C(c2ccccc2)[N+]([O-])=C1c1ccccc1</smiles>

29

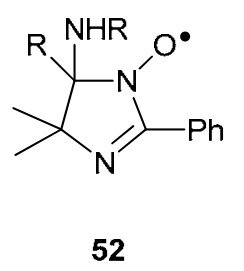

\section{Scheme 17}

In contrast to this, it has been concluded that the formation of spin adducts on ultraviolet irradiation or mild oxidation of indole nitrones, in the presence of a $N$-heteroaromatic base, proceeds according to the Forrester-Hepburn mechanism. ${ }^{48}$

\subsection{Oxidative fluorination of nitrones to $\alpha$-fluorosubstituted nitroxyl radicals}

Formation of nitroxyl radicals by the radical cation route was observed in the reactions of various nitrones with xenon difluoride in dry methylene chloride. ${ }^{46,49}$ The work $^{49}$ studies more than 40 nitrones, including TMPO and derivatives of 3-imidazoline-3-oxides (53) (Scheme 18), as well as $4 H$-imidazole $N$-oxides and $4 H$-imidazole $N$, $N$-dioxides, $2 H$-imidazole $N$-oxides and $2 \mathrm{H}$-imidazole $\mathrm{N}, \mathrm{N}$-dioxides for which ESR spectra of nitroxyl radicals containing one (compounds 54) or two (compounds 55) fluorine atoms at $\alpha-\mathrm{C}$ have been registered. In case of the 4-phenyl-3-imidazoline-3-oxide derivative (53, $\left.\mathrm{R}=\mathrm{C}_{6} \mathrm{H}_{5}, \quad \mathrm{X}=\mathrm{NNO}\right)$ the first stable monofluoro substituted nitroxyl radical has been isolated (Scheme 18). Nucleophilic substitution of fluorine by methoxy- and amino groups without affecting the radical center has made it possible to synthesize new $\alpha-C$ functional derivatives of stable nitroxyl radicals. ${ }^{46}$ 
<smiles>[R][X]1(C)C([R])(F)N(C)C(C)(C)C1(C)C</smiles>

54<smiles>[R]C1=[N+]([O-])C(C)(C)[X]C1(C)C</smiles>

53

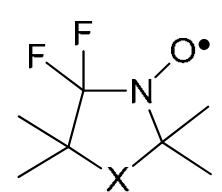

55

$$
\begin{aligned}
& X=N N O, \mathrm{NNO}_{2}, \mathrm{CH}_{2}(\mathrm{TMPO}) \\
& \mathrm{R}=\mathrm{H}, \mathrm{D}, \mathrm{CH}_{3}, \mathrm{CD}_{3}, \mathrm{C}_{2} \mathrm{H}_{5}, \mathrm{CH}_{2} \mathrm{Br}, \mathrm{CHBr}_{2},
\end{aligned}
$$$$
\mathrm{CHCl}_{2}, \mathrm{CHBrCH}_{3}, \mathrm{CHClCH}_{3}, \mathrm{CH}\left(\mathrm{OCH}_{3}\right)_{2}, \mathrm{C}_{6} \mathrm{H}_{5} \text {, }
$$$$
\mathrm{CONH}_{2}, \mathrm{CHO}, \mathrm{CH}=\mathrm{NC}_{4} \mathrm{H}_{9}-t, \mathrm{COOCH}_{3}, \mathrm{CN}, \mathrm{OCH}_{3}, \mathrm{SCH}_{3}
$$

\section{Scheme 18}

Later, ${ }^{50}$ under the similar conditions, the action of $\mathrm{XeF}_{2}$ on PBN and DMPO led to the similar spin adducts, proving radical cation mechanism. Unlike this reaction, the formation of fluorocontaining spin adducts when using a weaker oxidant such as $N$-fluorodibenzsulfonamide $\left[\left(\mathrm{PhSO}_{2}\right)_{2} \mathrm{~N}-\mathrm{F}\right]$ is believed to involve the Forrester-Hepburn mechanism.

\section{Conclusions}

The study of specific features of the chemistry of cyclic nitrones has made it possible not only to find new methods to activate the nitrone group of cyclic nitrones both in nucleophilic and electrophilic reactions and to synthesize earlier unknown and inaccessible $\alpha$-substituted cyclic nitrones and stable nitroxyl radicals, but also to get spectral and electrochemical evidence of the formation of intermediate particles on the basis of nitrones - radical cationes and dipolestabilized carbanion.

\section{References}

1. Katritzky, A. R.; Lagowski, J. M. Chemistry of the Heterocyclic N-Oxides, Academic Press: New York-London, 1971.

2. (a) Grigor'ev, I. A. Nitrones: Novel Strategies in Synthesis: In Nitrile Oxides, Nitrones, and Nitronates in Organic Synthesis: Novel Strategies in Synthesis; Feuer, H. Ed.; $2^{\text {nd }}$ Edn., Wiley: New York, 2008, Ch. 2, pp129-435. (b) Revuelta J., Cicchi, S.; Goti A.; Brandi A. Synthesis 2007, 486. (c) Merino, P. Nitrones and Cyclic Analogues in: Science of Synthesis: Heteroatom Analogues of Aldehydes and Ketones, Padwa, A. Ed., Thieme Verlag: StuttgartN.Y., 2004, Vol. 27, Ch. 27.13, pp.511-580. (d) Döpp, D.; Döpp H. In Houben-Weil. Methoden der Organischen Chemie. Band E 14b/Teil 2. Organische Stickstoff-Verbindungen mit einer C,N-Doppelbindung, von D. Klamann, H.; Hagemann, H., Ed.; Georg Thieme Verlag: Stuttgart-N.Y., 1990; pp 1372-1544. (e) Merino, P.; Franco, S.; Merchan, F. L.; Tejero, T. Synlett 2000, 442. (f) Lombardo, M.; Trombini, C. Synthesis 2000, 759. (g) Merino, P. C. R. Chimie 2005, 8, 775. 
3. (a) Bekker, D. A. In Organic Synthesis: Theory and Applications, Hudlicky, T., Ed., Elsevier, 1998; Vol.4, p155. (b) Davies, M. J. In Electron Paramagnetic Resonance, The Royal Society of Chemistry, 2002, Vol. 18, p 47. (c) Keana, J. F. W. In Spin Labeling in Pharmacology, Holtzman, J. L. Ed., Academic Press: Orlando, 1984, p 1. (d) Mottley, C.; Mason, R. P. In Biological Magnetic Resonance, Berliner, L. J.; Reuber, V. Eds., Plenum Press: N.Y., 1989; p 490. (e) Marples, K. R.; Knecht, K. T.; Mason, R. P. In Free Radicals in Synthesis and Biology, Minisi, F., Ed., Kluwer Academic: San Diego, 1989, p 423.

4. (a) Grishin, D. F.; Semenycheva, L. L.; Kolyakina, E. V. Russ. J. Appl. Chem. 2001, 74, 494.

(b) Grishin, D. F.; Semenycheva, L. L.; Kolyakina, E. V. Polym. Sci., Ser. A 1999, 41, 401.

(c) Grishin, D. F.; Semenycheva, L. L.; Sokolov, K. V.; Kolyakina, E. V. Polym. Sci., Ser. B 2000, 42, 189. (d) Grishin, D. F.; Ignatov, S. K.; Razuvaev, A. G.; Kolyakina, E. V.; Shchepalov, A. A.; Pavlovskaya, M. V.; Semenycheva, L. L. Polym. Sci., Ser. A 2001, 43, 989. (e) Kolyakina, E. V.; Semenycheva, L. L.; Grishin, D. F. Polym. Sci., Ser. A 2001, 43, 1223. (f) Grishin, D. F.; Semenycheva, L. L.; Pavlovskaya, M. V.; Sokolov, K. V. Russ. J. Appl. Chem. 2001, 74, 1594. (g) Pavlovskaya, M. V.; Kolyakina, E. V.; Polyanskova, V. V.; Semenycheva, L. L.; Grishin, D. F. Russ. J. Appl. Chem. 2002, 75, 1868. (h) Grishin, D. F.; Semenycheva, L. L.; Bulgakova, S. A.; Mazanova, L. M.; Kolyakina, E. V. Polym. Sci., Ser. A 2003, 45, 305. (i) Kolyakina, E. V.; Grishin, D. F.; Semenycheva, L. L.; Sazonova, E. V. Polym. Sci. Ser. A 2004, 46, 10.

5. Volodarskii, L. B.; Kutikova, G. A. Russ. Chem. Bull., Int. Ed. 1971, 20, 859.

6. Volodarskii, L. B.; Grigor'ev, I. A.; Kutikova, G. A. Zh. Org. Khim. 1973, 9, 1974.

7. Grigor'ev, I. A.; Volodarskii, L. B. Zh. Org. Khim. 1974, 10, 118.

8. Grigor'ev, I. A.; Volodarskii, L. B. Zh. Org. Khim. 1975, 11, 1328.

9. Martin, V. V.; Volodarskii, L. B.; Shchukin, G. I.; Vishnivetskaya, L. A.; Grigor'ev, I. A. Russ. Chem. Bull., Int. Ed. 1985, 34, 151.

10. Grigor'ev, I. A.; Shchukin, G. I.; Volodarskii, L. B. Zh. Org. Khim. 1975, 11, 1332.

11. Vasilevsky, S. F.; Klyatskaya, S. V.; Korovnikova, O. L.; Stass, D. V.; Amitina, S. A.; Grigor'ev, I. A.; Elguero, J. Tetrahedron Lett. 2004, 45, 7741.

12. Vasilevsky, S. F.; Klyatskaya, S. V.; Korovnikova, O. L.; Amitina, S. A.; Stass, D. V.; Grigor'ev, I. A.; Elguero, J. Tetrahedron 2006, 62, 4597.

13. Martin, V. V.; Volodarskii, L. B. Russ. Chem. Bull., Int. Ed. 1980, 29, 956.

14. Reznikov, V. A.; Volodarskii, L. B. Chem. Heterocycl. Compd. 1991, 27, 155.

15. Reznikov, V. A.; Volodarskii, L. B. Russ. Chem. Bull., Int. Ed. 1996, 45, 1699.

16. Volodarsky, L. B.; Grigor'ev, I. A.; Grigor'eva, L. N.; Kirilyuk, I. A. Tetrahedron Lett. 1984, $25,5809$.

17. Volodarskii, L. B.; Grigor'ev, I. A.; Grigor'eva, L. N.; Kirilyuk, I. A.; Amitina, S. A. Zh. Org. Khim. 1985, 21, 443.

18. Kirilyuk, I. A.; Grigor'ev, I. A.; Volodarskii, L. B. Russ. Chem. Bull., Int. Ed. 1987, 36, 1467.

19. Voinov, M. A.; Grigor'ev, I. A.; Volodarsky, L. B. Heterocycl. Commun. 1998, 4, 261. 
20. Voinov, M. A.; Grigor'ev, I. A.; Volodarsky, L. B. Tetrahedron 2000, 56, 4071.

21. Voinov, M. A.; Shevelev, T. G.; Rybalova, T. V.; Gatilov, Yu. V.; Burdukov, A. B.; Grigor'ev, I. A. Organometallics 2007, 26, 1607.

22. Voinov, M. A.; Grigor'ev, I. A. Tetrahedron Lett. 2002, 43, 2445.

23. Voinov, M. A.; Grigor'ev, I. A. Russ. Chem. Bull., Int. Ed. 2002, 51, 297.

24. Beak, P.; Meyers, A. I. Acc. Chem. Res. 1986, 19, 356.

25. Voinov, M. A.; Salnikov, G. E.; Genaev, A. M.; Mamatyuk, V. I.; Shakirov, M. M.; Grigor'ev, I. A. Magn. Reson. Chem. 2001, 39, 681.

26. Grigor'ev, I. A.; Shchukin, G. I.; Khramtsov, V. V.; Weiner, L. M.; Starichenko, V. F.; Volodarskii, L. B. Russ. Chem. Bull., Int. Ed. 1985, 34, 2169.

27. Grigor'ev, I. A.; Volodarsky, L. B.; Starichenko, V. F.; Shchukin, G. I.; Kirilyuk, I. A. Tetrahedron Lett. 1985, 26, 5085.

28. Grigor'ev, I. A.; Kirilyuk, I. A.; Starichenko, V. F.; Volodarskii, L. B. Russ. Chem. Bull., Int. Ed. 1989, 38, 1488.

29. Carloni, P.; Eberson, L. Acta Chem. Scand. 1991, 45, 373.

30. Eberson, L.; Nilsson, M. Acta Chem. Scand. 1993, 47, 1129.

31. Eberson, L. J. Chem. Soc., Perkin Trans. 2 1994, 171.

32. Alberti, A.; Carlone, P.; Eberson, L.; Greci, L.; Stipa, P. J. Chem. Soc., Perkin Trans. 2 1997, 887.

33. Eberson, L.; Persson, O. J. Chem. Soc., Perkin Trans. 2 1997, 1689.

34. Starichenko, V. F.; Kursakina, I. G.; Grigor'ev, I. A.; Volodarskii, L. B. Russ. Chem. Bull., Int. Ed. 1989, 38, 2642.

35. Kursakina, I. G.; Starichenko, V. F.; Kirilyuk, I. A.; Grigor'ev, I. A.; Volodarskii, L. B. Russ. Chem. Bull., Int. Ed. 1991, 40, 1774.

36. Kursakina, I. G.; Starichenko, V. F.; Grigor'ev, I. A. Russ. Chem. Bull., Int. Ed. 1994, 43, 428.

37. Bakunova, S. M.; Grigor'ev, I. A.; Kirilyuk, I. A.; Gatilov, Yu. V.; Bagryanskaya, I. Yu.; Volodarskii, L. B. Russ. Chem. Bull., Int. Ed. 1992, 41, 758.

38. 38. Shchukin, G. I.; Starichenko, V. F.; Grigor'ev, I. A.; Dikanov, S. A.; Gulin, V. I.; Volodarskii, L. B. Russ. Chem. Bull., Int. Ed. 1987, 36, 110.

39. Kirilyuk, I. A.; Grigor'ev, I. A.; Volodarskii, L. B. Russ. Chem. Bull, Int. Ed. 1991, 40, 1871.

40. Kirilyuk, I. A.; Grigor'ev, I. A.; Volodarskii, L. B. Russ. Chem. Bull. Int. Ed. 1991, 40, 1880.

41. Voinov, M. A.; Kursakina, I. G.; Grigor'ev, I. A. On effect of the nitrone group configuration on oxidation of aldonitrone to $\alpha$-methoxy substituted nitroxides, Abstracts of Papers of 6th International Symposium on Spin Trapping, Marseil, August 27-31, 2000, p 105.

42. Irtegova, I. G.; Starichenko, V. F.; Kirilyuk, I. A.; Grigor'ev, I. A. Russ. Chem. Bull., Int. Ed. 2002, 51, 2065.

43. Kursakina, I. G.; Starichenko, V. F.; Grigor'ev, I. A. Russ. Chem. Bull., Int. Ed. 1992, 41, 2003.

44. Acken, B. J.; Gallis, D. E.; Warshaw, J. A.; Crist, DeL.-R. Can. J. Chem. 1992, 70, 2076. 
45. Reznikov, V. A.; Burchak, O. N.; Vishnivetskaya, L. A.; Volodarskii, L. B.; Rybalova, T. V.; Gatilov, Yu. V. Russ. J. Org. Chem. 1997, 33, 1302; Chem. Abstr. 1998, 129, 148944.

46. Grigor'ev, I. A.; Volodarsky, L. B.; Starichenko, V. F.; Kirilyuk, I. A. Tetrahedron Lett. 1989, 30, 751.

47. Grigor'ev, I. A.; Starichenko, V. F.; Kirilyuk, I. A.; Volodarskii, L. B. Russ. Chem. Bull., Int. Ed. 1989, 38, 587.

48. Alberti, A.; Astolfi, P.; Dopp, D.; Greci, L.; Macciantelli, D.; Petrucci, R. New J. Chem. 2003, 27, 1045.

49. Grigor'ev, I. A.; Starichenko, V. F.; Kirilyuk, I. A.; Volodarskii, L. B. Russ. Chem. Bull., Int. Ed. 1989, 38, 841.

50. Eberson, L.; Persson, O. J. Chem. Soc., Perkin Trans. 2 1997, 893. 